\title{
Infância, educação e precariedade em Jane Eyre, Agnes Grey e Wuthering Heights
}

\author{
Ana Cristina Faria Menezes ${ }^{\mathrm{i}}$
}

\section{RESUMO}

Este artigo propõe investigar as diferentes infâncias figuradas nas obras Agnes Grey (1847), de Anne Brontë (1820-1849), Jane Eyre (1847), de Charlotte Brontë e Wuthering Heights (1847), de Emily Brontë (1818-1848). Dado que as irmãs de Haworth viram de perto as opressões trazidas pela Revolução Industrial e, antes disso, as complicações da agricultura capitalista (EAGLETON, 2005a; WILLIAMS, 2011), os entrelaçamentos entre o contexto histórico no qual viveram e a criação ficcional de suas personagens infantis contribuem para uma percepção mais refinada das respectivas precariedades (BUTLER, 2019) em jogo. Proponho, assim, que o ato de narrar tais infâncias, marcando-as materialmente quanto às suas distintas precariedades (BUTLER, 2019), expõe um sistema que precisa explorar vulnerabilidades para que possa crescer.

Palavras-chave: Infância; Era Vitoriana; Irmãs Brontë.

\begin{abstract}
This article proposes to investigate the different childhoods in Anne Brontë's (18201849) Agnes Grey (1847), Charlotte Brontë's Jane Eyre (1847), and Emily Brontë's (1818-1848) Wuthering Heights (1847). Since the Haworth sisters experienced closely the oppressions brought forth by the Industrial Revolution and, before that, the complications of a capitalist agriculture (EAGLETON, 2005a; WILLIAMS, 2011), the intertwining between historical context in which they lived and the fictional creation of children as characters contributes to a sharp perception of their respective precarities (BUTLER, 2019) at play. Thus, I propose that the act of narrating those childhoods, while materially marking their distinct precarities (BUTLER, 2019), exposes a system which must explore vulnerabilities in order to grow.
\end{abstract}

Keywords: Childhood; Victorian Age; Brontë Sisters.

No ano de 1847, as irmãs Anne (1820-1849), Charlotte (1816-1855) e Emily Brontë (1818-1848) publicaram, respectivamente, Agnes Grey, Jane Eyre e Wuthering Heights. Nesses romances, as autoras reconfiguraram algumas das tensões entre gênero,

\footnotetext{
${ }^{\mathrm{i}}$ Mestranda em Literaturas de Língua Inglesa no Programa de Pós-graduação em Letras da UERJ. https://orcid.org/0000-0003-0663-6678 | anacrismenezes@gmail.com
} 
classe e raça de seu tempo em suas complexas personagens infantis. Com base nessas distinções, este artigo propõe, a partir da leitura da filósofa contemporânea Judith Butler, pensar as condições de vulnerabilidade nas diversas reconfigurações de infância e criança trazidas pelas obras. Essas diferentes vulnerabilidades, já pensadas pela crítica feminista, são inscritas pelas Brontë não apenas em suas personagens femininas, mas também em suas personagens-infantis.

Aqui, a vulnerabilidade é entendida à luz de Vida Precária (2019), em que Butler distingue os conceitos de vida precária, constituição da qual todas as vidas humanas compartilham a partir do momento em que todas são mortais, e precariedades, circunstâncias nas quais algumas vidas seriam mais "matáveis" que outras. Raça, sexo, gênero e classes sociais diferentes seriam classificadores dessas precariedades materiais distintas (BUTLER, 2019, p. 49).

A distribuição dos diferentes contextos materiais nos quais as personagens crianças ou infantilizadas estão inseridas é um fator que seria, também, decisivo para se entender suas distintas vulnerabilidades. Para além disso, esses contextos seriam essenciais para se compreender o que seria visto como uma criança no século XIX. A pluralização do termo "infância", presente no título do meu artigo, se faz necessária visto que, como pontua a historiadora Ginger Frost, não há um tipo único de criança vitoriana, mas sim diversos desdobramentos de tipos de crianças que viveram nesse período em diferentes situações de infantilização (FROST, 2008, Loc192) - o que refletirá em suas precariedades.

O Bildungsroman, como gênero ou subgênero narrativo de caráter híbrido, traz a narrativa do comportamento e transformação do herói em face aos eventos vividos no mundo exterior. A tradição da narrativa de formação, também traduzida como "romance de aprendizagem" ou "de desenvolvimento", teve começo em 1794, a partir da obra de Goethe, Wilhelm Meister's Apprenticeship. Cristina Ferreira Pinto remonta às várias possibilidades e finalidades do Bildungsroman protagonizado e escrito por homens e questiona o porquê da "quase total ausência da mulher como personagem central" (PINTO, 1990, p. 12) no gênero.

Adrienne Rich, poeta e ensaísta feminista, em "The Temptations of a Motherless Woman" (2001), faz questão de marcar que o que Charlotte Brontë escreve não é um Bildungsroman, e sim "a história de vida de uma mulher que é incapaz de dizer Eu sou 
Heathcliff (como faz a heroína do romance de Emily) por conta de se sentir tão inalteravelmente ela mesma" (RICH, 2001, p. 470) ${ }^{12}$. Sandra M. Gilbert, conhecida por seus trabalhos no campo da crítica literária feminista, teoria feminista e crítica psicanalítica, vai além e propõe, assim como Ferreira Pinto, "um Bildungsroman particularmente feminino no qual problemas encontrados pela protagonista enquanto ela luta, contra o aprisionamento de sua infância, em direção ao quase impensável objetivo da liberdade na maturidade são sintomas das dificuldades" (GILBERT, 2001, p. 484) ${ }^{3}$. É, portanto, seguindo essa linha de raciocínio que Ferreira Pinto irá afirmar que "o 'mundo exterior' responsável pela formação do herói do 'Bildungsroman' seria, no caso da protagonista feminina, os limites do lar e da família, não havendo margem para o seu crescimento interior" (PINTO, 1990, p. 13).

Em Victorian Sexual Morality (1970), mulheres e crianças são colocadas como pares na questão da repressão e ignorância quanto às questões sexuais - lembrando aqui que, dependendo de sua classe social, uma mulher não casada aos 18 anos, como Agnes Grey, era considerada criança na Inglaterra vitoriana, visto que uma marca do ser infantil era a não sexualidade (ARIÉS, 1963, p. 119).

\begin{abstract}
A preocupação predominante [do Dr. Acton] é acreditar que as crianças são sexualmente puras e inocentes. A mesma preocupação por pureza e inocência colore sua visão da matriarca Vitoriana: 'As melhores mães. Esposas, e administradoras da casa, sabem pouco ou nada de indulgências sexuais. Amor ao lar, às crianças e aos afazeres domésticos, são as únicas paixões que elas sentem'.[...] Os Vitorianos queriam desesperadamente acreditar que suas esposas e mães eram sexualmente puras e, assim, eles colocavam mulheres em um pedestal do tamanho de uma torre para melhor idolatrá-las; nesse pedestal, mulheres serviam como lembretes constantes de que a sociedade as queria isoladas de si. (GOLDFARB, 1970, p. 40-41) ${ }^{4}$
\end{abstract}

$\mathrm{Na}$ escrita da narrativa das (im)possibilidades da mulher, a vulnerabilidade é perene. Essa afirmativa é restritiva, a mulher não se desenvolve plenamente - sua narrativa termina com ela casada ou morta, não havendo espaço para desenvolvimento interior, pois deve sentir-se completa apenas na situação da realização familiar. "A integração pessoal e a integração social são incompatíveis para a protagonista do 'romance de aprendizagem' tradicional” (PINTO, 1990, p. 16).

Uma vez que "as mulheres são crianças sem mãe em uma sociedade patriarcal" $\left(\mathrm{RICH}, 2001\right.$, p. 470) ${ }^{5}$ e "viver nesta ordem social é ser um órfão" (EAGLETON, 2005b, p. 91), Charlotte e Emily Brontë colocam a narrativa da criança órfã vulnerável 
como espelho para a narrativa da mulher vulnerável com Jane em Jane Eyre e Hareton, Catherine Linton e Linton, em Wuthering Heights. Nesse sentido, Butler explica que

\begin{abstract}
Se não se cria laços com uma criança, ela pode morrer e, sob certas condições, mesmo que esses laços sejam criados, ela pode estar ameaçada de não sobrevivência por outras razões. Portanto, o questionamento do apoio primário à vulnerabilidade primária é uma questão ética para a criança e para a infância. Mas existem consequências éticas mais amplas nessa situação que pertencem não apenas ao mundo adulto, mas à esfera política e a sua dimensão ética implícita. (BUTLER, 2014, p. 67)
\end{abstract}

Nas personagens crianças dos três romances comentados neste artigo, as irmãs Brontë marcam essas precariedades (BUTLER, 2019) tão distintas entre si. Aqui, a intervenção filosófica do pensamento de Judith Butler com seu conceito de uma vida precária comum e das precariedades materialmente distribuídas de forma desigual opera como principal teoria acerca da vulnerabilidade constitutiva do ser humano da qual me utilizarei neste artigo. Contrastando as vidas das crianças nos romances das Brontë, vemos a denúncia de opressões de um sistema que exclui tudo o que não é tido como padrão. A criança é o outro vulnerável de nós mesmos, que todos já foram, mas em algum momento esquecem, recalcam e idealizam nostalgicamente. Os adultos, que um dia já ocuparam esse lugar das crianças, mais vulneráveis, podem perpetuar o ciclo de reprodução de opressões que um dia sofreram na pele. É, portanto, na medida em que esse adulto se esconde por trás de seus mitos individualistas de autossuficiência do sujeito que a sua contraparte nas precariedades de cada criança dos romances das Brontë escancara o caráter crítico dessa literatura frente aos adultos vitorianos.

Ler a obra de Emily, Charlotte e Anne Brontë é se deparar com uma rede cuidadosamente tecida. Os fios entrelaçados nos mostram uma teia construída por diversas e diferentes camadas sociais, gêneros e idades, bem como o desconforto gerado pelo encontro desses diferentes fios. A confecção desses intrincados tecidos foi atravessada por ondas de mudanças sociais na Inglaterra do século XIX. Em relação às mudanças graduais quanto à posição da mulher e da criança podemos destacar os Factory Acts de 1840, em especial a Ten Hours Bill, que restringiu a jornada de trabalho de mulheres e crianças a dez horas diárias. Também podemos citar o estabelecimento do Governess's Benevolent Association, de 1843, e a fundação da Society for Prevention of Cruelty to Children, em 1844 (FROST, 2008; SHAWN, 2013). É possível flagrar um 
indício da precariedade de uma vida a partir do momento em que leis são especificamente criadas para protegê-la. $\mathrm{O}$ direito à vida da classe operária, de crianças e de mulheres precisa ser constantemente conquistado - são vidas que estão em risco contínuo. As irmãs de Haworth testemunharam de perto as mudanças que os ventos revolucionários se propuseram a trazer:

(...) elas viram de perto os efeitos da revolução industrial nas indústrias de lã de West Yorkshire, cujas bases eram o trabalho manual, incluindo ciclos viciosos de crescimento, quedas e desemprego. Haworth não era a represa selvagem e rural da fantasia popular, mas um lugar no qual as filhas do clérigo testemunham um sofrimento bastante visível. Pobreza, saúde precária e uma militância industrial furiosa eram tão evidente aqui quanto em cidades maiores como a vizinha Keighley. (RYLANCE, 2006, p. 157) ${ }^{6}$

Nesse exato período e lugar, ser alguém que escreve do campo, "ironicamente, era enunciar de um lugar histórico-mundial replete de significância" (EAGLETON, 2005a, p. xi) ${ }^{7}$. Em The English Novel (2005), Terry Eagleton escreve:

\footnotetext{
(...) os anos da infância das irmãs [Brontë] foram tempo de ruína para milhares de trabalhadores manuais espalhados em casebres nas colinas por toda a região - um aspecto dessa destruição dos tecelãos que Karl Marx descreve no Capital como a mais terrível tragédia da história da Inglaterra. Os anos seguintes das Brontës coincidem com greves, Cartismo, lutas contra as Corn Laws e manifestações pela reforma fabril. [...] suas vidas foram desenhadas por alguns dos mais típicos conflitos do início da Inglaterra Vitoriana - conflitos entre o rural e o urbano, colônia e metropole, Sul commercial e Norte industrial, a 'sensibildiade' feminine e o poder masculino. (EAGLETON, 2005b, p. 91) ${ }^{8}$
}

Em O Campo e a Cidade, datado de 1973, Raymond Williams pontua que a exploração das precariedades resultantes das mudanças na sociedade durante a Revolução Industrial não é exclusiva do período vitoriano. Antes disso, um capitalismo agrário altamente desenvolvido serviu de base para que a industrialização fosse possível. O trabalho rural infantil não costumava ser alvo de preocupação como o trabalho industrial em algum momento veio a ser. Contudo, com as práticas dessa agricultura capitalista, uma espécie particular de trabalho realizado por crianças no campo chamou a atenção suficiente para que o Agricultural Gangs Act de 1867 fosse decretado.

Williams pontua que diversas obras literárias se debruçaram sobre a nostalgia de um passado puro para tratar do campo como um lugar de ordem, tranquilidade e 
simplicidade em contraste a um presente industrial, caótico e agressivo. Ao analisar um trecho de poema escrito por John Clare (1793-1864), escreve

\begin{abstract}
Uma maneira de ver foi associada a uma fase perdida da vida, e a associação entre felicidade e infância deu origem a toda uma convenção, na qual apenas inocência e segurança, mas também paz e abundância, foram incorporadas, de modo indelével, primeiro à paisagem, e depois, numa extrapolação poderosa, a um período específico do passado do campo, agora ligado a uma identidade perdida, a relações e certezas perdidas, na lembrança do que é denominado, em contraposição a uma experiência presente, Natureza. (WILLIAMS, 2011, p. 235)
\end{abstract}

Podemos notar, então, que, para as Brontë, o campo não é um simples lugar de melancolia bucólica, mas um lugar também atravessado por todas as questões sociais aqui já destacadas. A infância para as irmãs não é locus da nostalgia, mas sim das precariedades.

Outro ponto de encontro e tensão entre eventos que cruzaram a biografia das autoras e suas reconfigurações em obras literárias é o trabalho, a atividade laboral. As três irmãs foram, em algum momento da vida, educadoras, trabalhando como professoras ou preceptoras. A profissão era uma possibilidade de sobrevivência para a mulher escolarizada e de classe média que não se casasse (RICH, 2001, p. 470). Em casas abastadas, as preceptoras, assim como as babás, passavam mais tempo com as crianças da família que os próprios pais. Ensinavam, principalmente, meninas, visto que os meninos da classe média alta eram, em sua maioria, mandados para internatos. $\mathrm{Na}$ Inglaterra vitoriana, a escolha de modelo educacional dependia parte de gênero, parte de classe (FROST, 2008, loc. 736-7).

Como ensina Frost (2008, Loc 737), na classe trabalhadora, meninas e meninos iam para as escolas mistas, em que se aceitavam ambos os sexos. As classes não eram separadas por idade e eram superlotadas. As crianças poderiam começar a ir para a escola muito novas, visto que as escolas eram um lugar em que mães trabalhadoras poderiam deixar seus filhos. O período dedicado à escolarização dessas crianças acabava, muitas vezes, quando o trabalho começava. Aos meninos de classe média e alta, o custo da escolarização era enxergado como investimento, visto que estes poderiam ocupar cargos de acordo com uma formação acadêmica específica. Assim, frequentavam boas escolas - em sua maioria, internatos - e poderiam dar sequência ao seu processo de escolaridade nas universidades. Enquanto isso, as meninas dessas 
mesmas classes eram educadas a fim de poderem demonstrar habilidades sociais - para muitos pais, o alto investimento na educação não valeria a pena, pois a melhor "carreira" que poderiam ter era de uma mulher casada. A educação das meninas era então de responsabilidade das preceptoras. Algumas meninas iam para a escola, mas essas seriam piores que a dos irmãos e muitos pais se preocupavam com as más influências que as colegas poderiam ser para suas filhas. A cultura, é, então, transformada numa commodity, "o ponto no qual um mundo interno de valor spiritual e um mundo externo de necessidades econômicas juntam-se de maneira incongruente" (EAGLETON, 2005b, p. 92) ${ }^{9}$.

Eagleton afirma que a preceptora desempenha um papel que captura as contradições de sua condição social (EAGLETON, 2005b, p. 92). Desenvolvendo esse argumento a professor Maria Conceição Monteiro anota que, ainda mais, a preceptora pode ser recebida com receio, visto que esta poderia alinhar-se às causas do proletariado, revoltando-se e indignando-se com sua situação, como também poderia ensinar tais ideias revolucionárias a seus pupilos, subvertendo os pilares burgueses (MONTEIRO, 2000, p. 29). O descontentamento com as classes superiores pode vir a ser uma perigosa afronta. Charlotte Brontë, em carta, escreve:

\footnotetext{
Eu me empenhei fortemente para achar agradável minha nova situação [...] Eu costumava pensar que eu gostaria de estar na agitação da alta sociedade ; mas eu já estou farta dela —é de aborrecer o trabalho de contemplar e escutar. Eu vejo com mais clareza do que jamais vi, que uma governanta doméstiva não tem existência, não é considerada um ser vivo e racional, com excessão da conexão que tem com os exaustivos deveres que ela tem de cumprir. (BRONTË, C. apud. GASKELL, 2005, p. 124) ${ }^{10}$
}

Em Jane Eyre, vemos claramente a posição incômoda da preceptora. Em lugar de penumbra, visível apenas o suficiente, mas não a ponto de ter qualquer importância, a protagonista passa por um desconfortável jogo de interações com Rochester e seus visitantes no capítulo XVII. Jane tem a certeza de que não pertence àquele lugar ao ouvir a conversa de Mrs. Dent e Blanche Ingram

\footnotetext{
"Minha querida, não mencione governantas; a palavra me deixa nervosa. Eu sofri um martírio por conta de suas incompetências e caprichos. Eu agradeço aos Céus que eu já encerrei o assunto com elas!"

A Sra. Dent aqui se inclinou sobre a madame e sussurrou algo em seu ouvido, eu suponho, pela resposta dada, que foi um lembrete de que uma da raça anatematizada estava presente.
} 


\begin{abstract}
“Tant pis!” disse a Madame, “Eu espero que a faça bem!" Então, em um tom mais baixo, mas ainda suficientemente alto para que eu pudesse ouvir, "Eu reparei nela; Eu sou uma juíza da fisionomia, e na dela eu vejo todos os defeitos de sua classe". (BRONTË, C. 2016, Loc13076) ${ }^{11}$
\end{abstract}

Na mesma situação narrada neste capítulo, Adèle, a pupila de Jane, é vista, mas não ouvida

\footnotetext{
"Bon jour, mesdames."

E a senhorita Ingram havia menosprezado-a com ar zombeteiro, e exclamou, "Oh, que pequena boneca!" (Ibid, Loc13004) ${ }^{12}$
}

A passagem revela, então, a incômoda relação entre a mulher preceptora e a sua pupila. Como ser apropriada? À menina-pupila deve-se oferecer a curadoria de material de leitura e estudo do que seria apropriado. A preceptora deveria portar-se de maneira apropriada. Na introdução de Tales from Shakespeare, publicada originalmente em 1807 por Charles e Mary Lamb, a diferença entre meninos e meninas em relação ao acesso à leitura é marcada para os meninos: “[pela permissão] de maneira geral, do uso das bibliotecas de seus pais em uma idade muito anterior a das meninas, eles frequentemente sabem as cenas de Shakespeare de cor, antes que suas irmãs sejam sequer permitidas olhar dentro desses livros viris" (LAMB, 2016, p. xii-xiii) ${ }^{13}$. Logo em seguida, há a recomendação de que os irmãos censurem o que não seria apropriado e presumam que haveria dificuldade de compreensão por parte das irmãs: “[...] explicando às suas irmãs aquelas partes que fossem mais difíceis, para elas, de entender [...] selecionando cuidadosamente o que é adequado para o ouvido de uma irmã mais nova" $\left(\right.$ LAMB, 2016, p. xiii) ${ }^{14}$. A menina pupila e a preceptora são constantemente vigiadas e censuradas.

\title{
Em Centuries of Childhood: A Social History of Family Life (1962), o
} historiador Pierre Ariès analisa como a maneira com a qual adultos se relacionavam com crianças mudou diversas vezes ao longo da história. No século XIX, a família não iria apenas estabelecer laços de honra e propriedade entre pais e filhos, mas também começaria a ser organizada em volta da criança. A criança foi a face de um movimento cristão moralizante. A família passaria, então, a estabelecer uma cumplicidade sentimental entre seus membros. Além disso, Ariès trata do processo de educação e seu impacto no relacionamento entre pais e filhos. No final do século XVII, as crianças já não eram educadas como se fossem uma versão pequena e incompleta de adultos. As 
escolas deram um senso de distância entre crianças e adultos, e o tipo de escolarização das crianças vitorianas era um marcador de suas diferentes infâncias (ref. completa).

Em Agnes Grey, de Anne Brontë, a distinção da escolaridade de crianças de uma mesma classe social por conta de gênero é explorada, assim como a figura da preceptora. Este artigo está sendo elaborado no ano seguinte às comemorações do bicentenário da irmã caçula de Haworth. A revisitação de sua obra traz uma imagem atualizada da autora: esta não estaria preocupada apenas com o caráter religioso de seus romances, como prevaleceu por anos na crítica, mas apresentaria, também, uma proposta de igualdade na educação de meninos e meninas, fazendo-se possível uma leitura protofeminista de seu texto. Marion Shaw (2013) questionará o porquê de Anne ter sido eclipsada por Charlotte Brontë quanto ao caráter de uma ideologia igualitária na sua obra:

\begin{abstract}
Charlotte Brontë foi por muito tempo aclamada como a pioneira do romance feminista do século dezenove e alguns dos protestos de Jane Eyre foram a apaixonante inspiração para escritos feministas do século vinte: 'mulheres sentem tanto quanto os homens', 'Eu me importo comigo mesma', 'Leitor, eu casei com ele', foram como chamados estridentes para futuras gerações de mulheres. Por quê Anne Brontë não foi aclamada de maneira semelhante quando em muitos aspectos ela é a romancista mais ousada? É talvez o aspect religioso lançado no propósito de Anne Brontë em seus romances que disfarçou o quão feministasuas heroínas e suas narrativas são. O dela é um feminismo moral, quase accidental frente à busca por uma vida de propósito religioso no qual a equidade das almas frente a Deus encontra um eco secular emu ma razoável, respeitosa e igualitária entre os sexos no casamento. Suas visões sobre a educação das crianças relacionam-se com uma convicção apaixonada por esse ideal. (SHAW, 2013, p. 337) ${ }^{15}$
\end{abstract}

A partir das reflexões acima, podemos retornar a Agnes Grey para pensar a história de sua personagem-título. Agnes decide exercer a profissão de preceptora após ver seu pai, Richard Grey, adoecer e se endividar por conta de um investimento mercantil falho. Alice Grey, mãe de Agnes, perdeu o status de lady por escolher se casar com Mr. Grey e, aparentemente, entende a escolha da filha, embora não pareça concordar plenamente com a ideia de Agnes se "submeter" ao trabalho de preceptora. Apesar disso, Alice ajuda sua filha a encontrar famílias que possam acolher Agnes dignamente e também convence Mr. Grey de que Agnes está tomando uma boa decisão em benefício próprio e não apenas por conta da ruína financeira da família causada por seu pai. Agnes sai de casa, então, com a proposta de se educar e de educar outros. A visão romântica e ao mesmo tempo infantil da educação vai se dissolvendo ao longo da 
prática preceptorial da personagem. Paralelamente, podemos pensar que, como afirma a pesquisadora Marcela Santos,

\begin{abstract}
[a]lém da discussão e propagação da doutrina da salvação universal, um grande pilar no projeto ficcional de Anne Brontë gira em torno da preocupação da autora com a educação. Anne trabalhou como preceptora por mais tempo do que as irmãs, tendo passado quase seis anos longe de casa (Adams; Smith, 2020, p. 210). A defesa de uma educação igualitária para meninos e meninas e os possíveis efeitos negativos decorrentes de ênfases ditadas pelo sexo da criança são encenados em Agnes Grey na figura da família Bloomfield e debatidos por Gilbert Markham e Helen Huntingdon em The Tenent of Wildfell Hall. As influências de uma família excessivamente indulgente ou severa também são interrogadas, além da precariedade da posição da preceptora quando o projeto ditado pela família não é executado conforme o planejado. (BRIGIDA, 2020 p. 137)
\end{abstract}

Ao longo da narrativa, fica claro que a preceptora "pode olhar para cima e para baixo na hierarquia social" (EAGLETON, 2005b, p. 92). Agnes faz duras críticas às famílias para quem trabalha, questionando papéis de gênero e o tratamento que recebe tanto dos patrões quanto dos empregados: "Os servos, vendo o quão baixa era a estima que a governanta possui perante os pais e as crianças, regulavam seu comportamento pelo mesmo padrão" (BRONTË, A. 2016, Loc 1138) ${ }^{16}$. O pesquisador Sandro Jung propõe que o final do romance traga uma mensagem de esperança para um novo futuro em relação à educação, no qual aqueles que têm o poder de mudar as economias e distribuição do conhecimento podem criar uma sociedade justa e igualitária (JUNG, 2011, p. 233).

Em Jane Eyre, também vemos traços do Bildungsroman retorcido e feminino (PINTO, 1990). O romance começa com a pequena Jane vivendo sob a custódia da família Reed. Sempre agregada e segregada, como formula Conceição Monteiro (2000, p. 31), a criança-Jane é colocada em seu lugar de alguém inferior a todos na casa e, por vezes, é até associada a animais: "Não; você é menos que um servo, porque você não faz nada para o seu sustento. Aqui, sente-se e pense sobre a sua malvadeza" (BRONTË, C. 2016, Loc10101 ${ }^{17}$. As crianças habitantes de Gateshead Hall demonstravam ter total noção de seu lugar de classe e gênero, visto suas ações ou seus silêncios. Após ser constantemente maltratada, principalmente por John Reed, irmão mais velho da família, Jane, durante um castigo, passa por um momento de despertar no red room. Jane enxerga a impossibilidade de continuar existindo naquele espaço e toma coragem para expressar diretamente o ódio que sente por sua tia e também o desejo de ser mandada 
para uma escola. A narrativa segue, então, Jane em Lowood, um internato para jovens órfãs e/ou pobres. Lá, o leitor acompanha a descrição de uma série de abusos relacionados às condições de ser mulher, criança ou infantilizada e pobre. A precariedade das internas é ainda mais marcada no capítulo VII, no qual as filhas do reverendo visitam a instituição e o contraste entre meninas pobres e ricas é direto. Jane segue questionadora e insatisfeita. Novamente, a professora Conceição Monteiro nos ensina que "A rebelião de Jane traduz a luta política entre gender e gerações. Jane Eyre luta contra a dominação do outro, representado pela figura paterna do reverendo [Brocklehurst]" (MONTEIRO, 2000, p. 78).

Com o desejo de ir ver o mundo fora da situação de interna - agregada, aluna, professora - Jane sai rumo a Thornfield. Lá, deve se ocupar da educação da pequena Adèle. Como educadora, Jane não tem grandes desafios com a menina, visto que não há sinais aparentes de desrespeito. Contudo, é necessário observar também a frágil posição de Adèle em Thornfield Hall. Além de desconhecer seu provável parentesco com Rochester, ele mesmo duvida da ligação sanguínea entre os dois. Imputa-se o papel de agregada em Adèle, uma vez que Rochester não tem qualquer obrigação de responsabilidade sobre ela. Jane pode ver em Adèle o que ela própria poderia ter sido na casa dos Reeds. Adèle não parece esperar de seu tutor (pai?) grande proximidade e cumplicidade, mas há um mínimo de respeito e cuidado, o que Jane não teve com a família Reed.

Finalmente, há o romance de Emily Brontë, Wuthering Heights. Narrado em diferentes enquadres, o leitor pode ter a impressão de que Nelly Dean, uma mulher e criada, só tem direito ao poder da narrativa por estar embutida na narrativa do novo inquilino de Thrushcross Grange, Mr. Lockwood, e por não ser a grande protagonista da história que conta. Após a breve leitura do diário de Catherine Earnshaw, o inquilino crê ter visto o fantasma de Catherine, agora Linton, e fica intrigado com a história das famílias que ali habitam e habitaram. Nelly Dean tem, então, o grande poder de recortar e costurar a trama. A mulher servente, que também foi uma criança em um momento do romance, dado que tinha a mesma idade de Hindley, o irmão mais velho da família Earnshaw: "'Hindley Earnshaw! [...] Ele morreu fiel ao seu personagem: bêbado como um lorde. [...] Ele mal tinha vinte e sete, parece; Essa é a sua [Nelly Dean] propria 
idade: quem teria imaginado que você nasceu apenas um ano depois dele?"' (BRONTË, E. 2016, Loc42074) $)^{18}$.

O comentário sobre precariedades pode ser tecido a começar pelas diferenças das duas casas que protagonizam o romance e, consequentemente, sobre aqueles que as habitam. Sobre os contrastes entre Thrushcross Grange e Wuthering Heights, Raymond Williams aponta a primeira como sendo "protegida e vivendo de aluguéis" (WILLIAMS, 2011, p. 294) enquanto a segunda aparece "vulnerável e sustentada pelo trabalho" (Ibid). Para Eagleton, Grange era um lugar de ordem e civilidade, mas tal que "vela o trabalho duro e a exploração sobre os quais essas virtudes fundaram suas bases" (2005a, p. xvi) ${ }^{19}$, enquanto a brutalidade em Heights é escancarada.

Nelly Dean é uma personagem com a qual podemos enxergar que a questão do trabalho infantil não era exclusiva da cidade, como nos informa Ginger Frost: "A grande maioria das crianças sempre trabalhou, enquanto muitas cresceram como camponeses e ajudaram nas plantações o mais cedo que podiam. O que diferia na era industrial, então, não era o fato de haver trabalho, mas o seu caráter" (FROST, 2008, p. 16) ${ }^{20}$. Também a partir de Nelly, podemos ver a diferença em relação aos Earnshaw e aos Linton, além de Heathcliff, quanto às suas infâncias. Como, segundo Frost (Ibid), o trabalho significava o fim da infância, percebemos que Nelly deixa de narrar a si mesma como criança muito cedo na narrativa, enquanto Hindley é considerado adulto apenas quando sai de casa para estudar e volta casado com France. $\mathrm{O}$ amadurecer de Cathy tem relação direta à sua estada na casa dos Linton, onde parece haver um despertar de consciência de classe e a decisão de que se casaria com Edgar. Isabella é uma criança até casar-se com Heathcliff, uma vez que, para a maioria das mulheres de classe média ou alta no século XIX, o fim da infância se daria no casamento. Já Heathcliff,

Ele é, obviamente, proletário em aparência, mas a obscuridade de suas origens também o liberta de qualquer papel social preciso; como Nelly Dean imagina, mais tarde, ele poderia igualemente ser um príncipe. Ele é levado para Heights por nenhuma razão senão para ser arbitrariamente amado; e nesse sentido ele é um marco da resposta dos outros, uma força liberadora para Cathy e um bloco desajeitado para os outros. (EAGLETON, 2005a, p. $102)^{21}$

Sua nebulosa origem - cigano ou irlandês, como sugere Eagleton (2005b, p. 90), mas, de toda forma não inglês — permite a amizade com Cathy, mas não o casamento. 
Cathy e Heathcliff não teriam direito a qualquer patrimônio, logo aos dois era permitido que ultrapassassem a "estrutura doméstica" (EAGLETON, p. 103). Contudo, a liberdade se estende apenas até certo ponto uma vez que, ao tomar consciência de sua condição precária de mulher não herdeira, Cathy escolhe casar-se com Linton e Heathcliff se revolta usando do jogo da herança para castigar quem um dia o castigou.

A recuperação das personagens infantis nos romances comentados ao longo deste artigo se faz relevante dado o entrelaçamento das noções de vida precária e precariedades com os fios narrativos que compõem as obras e o contexto histórico das irmãs Brontë. Nessas narrativas, as infâncias são marcas de vulnerabilidades que, na medida em que espelham e reconfiguram o contexto social ao seu redor, também denunciam um sistema falido que, para funcionar, precisa, necessariamente, produzir situações de opressão. Se as precariedades retornam na filosofia contemporânea enquanto tema incontornável, a literatura das irmãs Brontë figura constitui um terreno fértil a ser revisitado.

\section{Referências}

ARIÈS, Philippe. Centuries of Childhood: A Social History of Family Life., Tradução de Robert Baldick. New York: Alfred A. Knopf, 1962.

BUTLER, Judith. Vida precária: os poderes do luto e da violência. Belo Horizonte: Autêntica Editora, 2019.

BRIGIDA, Marcela Santos. "What is it that constitutes virtue, Mrs. Graham?": uma releitura do projeto ficcional de Anne Brontë no ano do bicentenário". Escritos discentes em literaturas de língua inglesa, Letra Capital: Rio de Janeiro, v. XIII, p. 130$139,2020$.

BRONTË, Anne; BRONTË, Charlotte; BRONTË, Emily. The Complete Novels of the Brontë Sisters. New York: Golden Deer Classics, 2016. Kindle Edition

EAGLETON, Terry. Myths of Power: A Marxist Study of the Brontës. London: Palgrave Macmillan, 2005a.

EAGLETON, Terry. The English Novel: An Introduction. Oxford: Blackwell, 2005b.

FROST, Ginger. Victorian Childhoods (Victorian Life and Times). Westport: Praeger Publishers, 2008. Kindle Edition.

GASKELL, Elizabeth. The Life of Charlotte Brontë. New York: Barnes Noble Classics, 2005. 
GILBERT, Sandra M. “A Dialogue of Self and Soul: Plain Jane's Progress". In: BRONTË, Charlotte. Jane Eyre. Ed. Richard J. Dunn. Norton 3rd ed. New York: Norton \& Co., 2001.

GOLDFARB, Russell M. Sexual Repression and Victorian Literature. Lewisburg: Bucknell University Press, 1970.

JUNG, Sandro. "Knowledge Economies in Agnes Grey". Brontë Studies, 36(v. 3), p. 224-234, 2011.

LAMB, Chales and Mary. Tales from Shakespeare. UK: Penguin Random House, 2016.

MONTEIRO, Maria Conceição. Sombra errante: a preceptora na narrativa inglesa do século XIX. Rio de Janeiro: Editora Universidade Federal Fluminense, 2000.

RICH, Adrienne. “Jane Eyre: The Temptations of a Motherless Woman”. In: BRONTË, Charlotte; DUNN, Richard J (Ed.) Jane Eyre. Norton 3rd ed. New York: Norton \& Co., 2001.

RYLANCE, Rick. “'Getting on': Ideology, personality and the Brontë characters". In: H. Glen (Ed.), The Cambridge Companion to the Brontës. Cambridge: Cambridge University Press, 2006.

PINTO, Cristina Ferreira. O Bildungsroman feminino: Quatro exemplos brasileiros. São Paulo: Editora Perspectiva, 1990.

SHAW, Marion. “Anne Brontë: A Quiet Feminist”. Brontë Studies, 38(v. 4), p. 330338, 2013.

WILLIAMS, Raymond. O campo e a cidade: na história e na literatura; tradução Paulo Henriques Britto. São Paulo: Companhia das Letras, 2011.

Recebido em: 26/01/2021

Aceito em: 25/02/2021

\footnotetext{
${ }^{1}$ Todas as traduções não sinalizadas nas referências são de minha autoria.

2 "the life story of a woman who is incapable of saying I am Heathcliff (as the heroine in Emily's novel does) because she feels so unalterably herself"

3 "a distinctively female Bildungsroman in which problems encountered by the protagonist as she struggles from imprisonment of her childhood toward an almost unthinkable goal of mature freedom are symptomatic of difficulties"
} 


\footnotetext{
4 “"[Dr. Acton's] overriding concern is to believe that children are sexually pure and innocent. The same concern for purity and innocence colors his view of the Victorian matron: 'The best mothers. Wives, and managers of the households, know little or nothing of the sexual indulgences. Love of home, children and domestic duties, are the only passions they feel'.....] The Victorians wanted desperately to believe that their wives and mothers were sexually pure and so they placed women on a towering pedestal the better to idolize them; on the pedestal, women served as constant reminders that society wanted them isolated."

5 "women are motherless children in a patriarchal society"

6 "they saw vividly the effects of the industrial revolution on the craft-based wool industries of West Yorkshire, including vicious cycles of growth, slump and unemployment.Haworth was not the wild, rural backwater of popular fantasy, but a place in which the clergyman's daughters witnessed very visible distress.Poverty, poor health and outraged industrial militancy were as evident here as in larger towns such as neighbouring Keighley.”

7 “ironically, was to spring from a setting of world-historical significance"]

8 “'(...) the years of the sisters' childhood were a time of ruination for thousands of handworkers scattered in hill-cottages throughout the region - one aspect of that destruction of the handloom weavers which Karl Marx described in Capital as the most terrible tragedy of English history. The Brontës' later years coincided with strikes, Chartism, struggles against the Corn Laws and agitations for factory reform. [...] their lives were shaped by some of the most typical conflicts of early Victorian England - conflicts between rural and urban, colony and metropolis, commercial south and industrial north, female 'sensibility' and male power"

9 "the point at which an inner world of spiritual value and an outer world of economic necessity come incongruously together"
}

10 "I have striven hard to be pleased with my new situation [...]I used to think I should like to be in the stir of grand folks' society; but I have had enough of it - it is dreary work to look on and listen. I see more clearly than I have ever done before, that a private governess has no existence, is not considered as a living rational being, except as connected with the wearisome duties she has to fulfil."

11 "My dearest, don't mention governesses; the word makes me nervous. I have suffered a martyrdom from their incompetency and caprice. I thank Heaven I have now done with them!"

Mrs. Dent here bent over to the pious lady and whispered something in her ear; I suppose, from the answer elicited, it was a reminder that one of the anathematised race was present.

"Tant pis!" said her Ladyship, "I hope it may do her good!" Then, in a lower tone, but still loud enough for me to hear, "I noticed her; I am a judge of physiognomy, and in hers I see all the faults of her class."

12 "Bon jour, mesdames."

And Miss Ingram had looked down at her with a mocking air, and exclaimed,

"Oh, what a little puppet!"

13 “" $[. .$.$] it has been generally permitted the use of their father's libraries at a much earlier age than girls$ are, they frequently have the best scenes of Shakespeare by heart, before their sisters are permitted to look into this manly book"

14 “ $[\ldots]$ explaining to their sisters such parts are hardest for them to understand [...] carefully selecting what is proper for a young sister's ear"

15 "Charlotte Brontë has long been acclaimed as the pioneer feminist novelist of the nineteenth century and some of Jane Eyre's protestations have been the passionate inspiration for twentieth century feminist writings: 'women feel just as men do', 'I care for myself', 'Reader, I married him', have been the clarion calls for later generations of women. Why hasn't Anne Brontë been similarly acclaimed when in many respects she is the more daring novelist? It is perhaps the religious cast to Anne Brontë's purpose in her novels which has disguised just how feminist her heroines and her narratives are. Hers is a moral 
feminism, almost accidental to the quest for a life of religious purpose in which the equality of souls before God finds a secular echo in a reasonable, respectful and egalitarian relationship between the sexes in marriage. Her views on the education of children relate with passionate conviction to this ideal."

16 "The servants, seeing in what little estimation the governess was held by both parents and children, regulated their behaviour by the same standard"

1717 "No; you are less than a servant, for you do nothing for your keep. There, sit down, and think over your wickedness"

18 “'Hindley Earnshaw! [...] He died true to his character: drunk as a lord. [...] He's barely twenty-seven, it seems; that's your [Nelly Dean] own age: who would have thought you were born in one year?"'

19 "veils the hard labour and exploitation on which these virtues are based"

20 "The vast majority of children had always worked, as most grew up as peasants and helped on farms as soon as they could. What differed in the industrial age, then, was not the fact of the work but its character"

21 "He is, of course, proletarian in appearance, but the obscurity of his origins also frees him of any exact social role; as Nelly Dean muses later, he might equally be a prince. He is ushered into the Heights for no good reason other than to be arbitrarily loved; and in this sense he is a touchstone of others' responses, a liberating force for Cathy and a stumbling block for others.” 